\title{
TRABALHO, TECNOLOGIA E INOVAÇÃO NA INDÚSTRIA DE PROCESSO CONTIINUO: AS TRANSFORMAÇÕES NA INDÚSTRIA BRASILEIRA DE CELULOSE DE MERCADO.
}

\author{
LABOR, TECHNOLOGY AND INNOVATION IN CONTINUOUS \\ PROCESS INDUSTRIES: TRANSFORMATIONS IN THE \\ BRAZILIAN MARKET PULP
}

Data de submissão: 28-12-2012 Aceite: 11-06-2014

Glicia Vieira dos Santos ${ }^{1}$ Angela Maria Carneiro Araújo² Leda Maria Caira Gitahy ${ }^{3}$

\section{RESUMO}

O artigo se propõe a analisar os efeitos da globalização e da reestruturação produtiva para a organização da produção, os trabalhadores e os sindicatos do setor brasileiro de papel e celulose. Trata-se de um setor internacionalizado, cujas relações comerciais se dão entre países. Os procedimentos metodológicos adotados para a elaboração deste trabalho compreenderam: pesquisa bibliográfica, pesquisa de campo, pesquisa documental, análise de estatísticas sobre o mercado de trabalho, visitas a fábricas e sindicatos e entrevistas. $O$ argumento central é a de que as mudanças associadas à globalização têm um rebatimento importante no interior das fábricas, modificando a correlação de forças entre os diversos atores envolvidos na produção e tendo na participação da mão-de-obra uma mediadora não desprezível. A reestruturação que ocorre nesta indústria a partir da segunda metade dos anos 90 é parte do processo de globalização, é 'sistêmica'. Isto porque, alcançou um amplo espectro: desde a reestruturação das cadeias produtivas no plano internacional, passando pela redefinição das estratégias gerenciais das empresas, ultrapassando os limites de suas fronteiras com mudanças nas relações com as comunidades locais e as firmas que integram a cadeia de fornecimento de produtos e serviços e, contemplando ainda, a reformulação das estratégias sindicais. Decisões gerenciais 'técnicas' que ocultam uma dimensão 'política' alteraram as relações de poder entre chefes, engenheiros e trabalhadores do chão-de-fábrica. Os avanços tecnológicos e as transformações no plano da organização do trabalho e das políticas de recursos humanos são aqui entendidos como medidas integradas que se complementam entre si para influenciar a participação e o aumento da produtividade num contexto marcado pelo aumento da competitividade e da concorrência.

Palavras-chaves: Globalização; Trabalho; Emprego; Qualificação; Trabalhadores.

\footnotetext{
1 Possui graduação em Administração pela Universidade Federal do Espírito Santo, UFES, Mestrado em Política Científica e Tecnológica pela Universidade Estadual de Campinas, UNICAMP e Doutorado em Ciências Sociais pela Universidade Estadual de Campinas, UNICAMP. Vitória. Espírito Santo. Rio Grande do Sul. Brasil. E-mail: glicia.vieira@gmail.com

2 Possui Graduação em Ciências Sociais pela Universidade de Brasília, UnB e Doutorado em Ciências Sociais pela Universidade Estadual de Campinas, UNICAMP. Campinas. São Paulo. Brasil. E-mail: araujo@unicamp.br

3 Possui Graduação em Ciências Sociais pela Uppsala Universitet, Mestrado em Ciências Sociais pela Uppsala Universitet e Doutorado em Sociologia pela Uppsala Universitet, Suécia. Atualmente é Professor da Universidade Estadual de Campinas. São Paulo. Brasil. E-mail: leda@ ige.unicamp.br

$\left(^{*}\right)$ As autoras agradecem a contribuição dos pareceristas: o dispêndio voluntário de seu valioso tempo, suas preciosas considerações, seu conhecimento, experiência, paciência, polidez e esmero foram fundamentais para o aperfeiçoamento do artigo.
} 


\section{ABSTRACT}

The article aims to analyze the effects of globalization and productive restructuring to the organization of production, workers and trade unions of the Brazilian pulp and paper. This is an industry internationalized, whose trade relations is made between countries. The methodological procedures included: literature research, field research, documents research, analysis of statistics on the labor market, visits to companies and unions, and interviews. The central argument is that the changes associated with globalization have a major bounce inside the factories, changing the balance of power between the various actors involved in the production. Worker participation is an important asset for the companies surveyed. The restructuring that occurs in this industry (from the second half of the 90s) is 'systemic', crosses the boundaries of firms, reverberating throughout the production chain: restructuring of supply chains internationally, redefinition of managerial strategies of companies, changes in relationships with local communities, changes in relationships with firms that comprise the supply chain of products and services and the reformulation of trade union strategies. Management decisions 'techniques' that hide a dimension 'policy' changed the power relations between chiefs, engineers and workers of the factory floor. Technological advances and changes in the plan of work organization and human resource policies are understood here as integrated measures that complement each other to influence participation and productivity growth in a context marked by increasing competitiveness and competition.

Keywords: Globalization; Labor; Employment; Qualification; Workers.

\section{INTRODUÇÃO}

Nos últimos anos o debate em torno do adjetivo 'global' e da globalização (e/ou mundialização) enquanto um processo de transformação marcado por mudanças econômicas, sociais, políticas e culturais tem ganhado grande vulto. Entretanto, conquanto tenha havido considerável avanço nas discussões acadêmicas acerca do processo de globalização, principalmente nos anos 90 , privilegiando a interdisciplinaridade de enfoques e a pluralidade de abordagens, existem inúmeras divergências no que tange ao seu conceito, suas causas, seus efeitos, grau e extensão das mudanças.

Apesar da existência de polarizações entre diferentes trajetórias teóricas, existe um consenso tanto entre os defensores quanto entre os críticos da globalização no que se refere pela menos aos quatro processos de mudanças em curso, a saber: i) a intensificação do comércio internacional verificada a partir de meados dos anos 70; ii) a desregulamentação e internacionalização dos mercados financeiros no início dos anos 80; iii) a revolução tecnológica nos transportes, nas comunicações e no processamento e transmissão de informações (inclusive com efeitos no interior das fábricas); e, iv) o crescente investimento externo direto realizado pelas grandes empresas multinacionais (Araújo, 2001).

Um efeito importante da intensificação do comércio internacional e do crescimento do investimento externo direto é a transformação na divisão internacional do trabalho orientada por um processo de expansão 'global' das cadeias produtivas, hierarquização dos espaços produtivos e especializações comerciais e tecnológicas entre regiões e países ao redor do planeta. Neste sentido, a nova divisão internacional do trabalho estaria associada a uma nova geo-economia que centralizaria a produção baseada em capital intensivo e alto valor agregado nos países da tríade (Europa, América do Norte e Japão/Leste asiático) e concentraria a produção baseada em trabalho intensivo e baixo valor agregado nos países periféricos e semi-periféricos (Dicken, 1998; Waddington, 1999; Scholte, 2000; Araújo, 2001; Hirst e Thompson, 1998; Held et alli, 2000; Pochmann, 2002).

Outro aspecto a ser salientado como decorrência do recrudescimento das trocas internacionais e do investimento externo refere-se às modificações realizadas nos regimes regulatórios com alteração na legislação e na política econômica de países, bem como desregulamentação e 
flexibilização dos mercados de trabalho, visando eliminar restrições para atrair e manter o capital estrangeiro (Waddington, 1999; Moreau e Trudeau, 1998; Lévesque e Murray, 2003). As modificações nos regimes regulatórios associam-se as alterações nos regimes produtivos com a difusão e introdução de formas alternativas de sistemas 'pós-fordistas' de gestão da empresa e da produção (Waddington, 1999; Araújo, 2001; Lapointe, 1996; 2000-a; 2000-b; 2000-c; 2002-c; Langlois, 1996).

Cada um destes elementos tem conseqüências para o trabalho e os trabalhadores em geral e para aqueles lotados em setores específicos. A literatura especializada em 'globalização e trabalho' tem indicado uma série de tendências gerais como decorrência do aumento da influência das corporações multinacionais vis-à-vis o posicionamento dos trabalhadores (Araújo, 2001:42-44). Além disso, para Lévesque e Murray (2003:4-5), este processo estaria virando muitas práticas, costumes e o cotidiano dos atores.

Nesta perspectiva, Held et alli (2000) destacam como efeitos deste processo: o rebaixamento dos salários e das condições de trabalho, a perda de postos de trabalho qualificados, o aumento do desemprego nos países centrais marcado por transferências de produção e tecnologia para outros países visando baixos salários e baixo custo de mão-de-obra, o aprofundamento das diferenças salariais entre trabalhadores qualificados e não-qualificados tanto no interior quanto entre países e a improvável convergência dos salários no plano mundial. Estes autores consideram os trabalhadores como atores secundários sujeitos às conseqüências, em geral negativas, da globalização.

Já autores como Waddington (1999) e Harvey (2003), entre outros, apontam para a alteração da composição da força-de-trabalho com redução do emprego industrial e crescimento de postos de trabalho no setor de serviços, a queda na proporção de trabalhadores do sexo masculino empregados em grandes plantas industriais, a crescente proporção de empregos subcontratados, temporários e em tempo parcial destinado às mulheres em pequenos estabelecimentos, a possibilidade da perda de influência política e econômica dos trabalhadores, a queda nas taxas de sindicalização, a perda da influência política dos sindicatos sobre os trabalhadores e o maior envolvimento do trabalhador com as empresas; destacando a necessidade, por parte das entidades sindicais, do desenvolvimento de novas estratégias de recrutamento e representação visando incorporar os diversos segmentos da força-de-trabalho (mulheres, imigrantes, trabalhadores subcontratados, etc.). Apesar disso, esses autores avaliam os trabalhadores como sujeitos diretamente implicados no processo de globalização, pois na sua relação com suas empresas (sejam elas multinacionais, transnacionais ou domésticas), com os governos nacionais e com as instituições supranacionais de governança, são capazes de tomar iniciativas e fazer escolhas e, assim, influenciar a difusão e/ou limitar a globalização, bem como a forma pela qual o processo de globalização se desenvolve e afeta distintos países, regiões, setores econômicos e outros trabalhadores.

As transformações mencionadas têm se combinado e produzido efeitos específicos no Brasil, afetando a natureza do tecido produtivo aqui existente, o perfil e a identidade dos atores vinculados à produção, bem como os espaços institucionais onde eram e são representados e negociados os interesses desses atores (Guimarães, 2004; Araújo et alli, 2004; Abramo, 2000). Quanto ao primeiro item, nota-se o estabelecimento de novos mecanismos decisórios tanto no gerenciamento de negócios quanto na formulação de estratégias corporativas das empresas. Sendo possível também observar um processo de re-espacialização de investimentos e de fábricas, com algumas empresas brasileiras ampliando a abrangência de sua área de atuação tanto no interior do território nacional quanto na esfera internacional, além de diversificarem o escopo de suas atividades produtivas. No que se refere ao segundo item, é possível perceber mudanças na composição da mão-de-obra e na estrutura das carreiras com a emergência de novas categorias ocupacionais. No que tange ao terceiro item, cabe assinalar o surgimento de novos desafios para 
o movimento sindical e a ação coletiva, a emergência de novas formas institucionais de regulação de interesses associadas ao processo de redemocratização político-institucional do país, assim como o surgimento de novas institucionalidades elaboradas a partir dos processos recentes de transformação sócio-econômica (Guimarães, 2004).

Para ilustrar a análise desse conjunto de fenômenos elegemos o setor brasileiro de celulose de mercado. Trata-se de um setor produtivo pouco estudado pela literatura especializada e que apresenta características relevantes para analisar o tema em presença.

A literatura internacional tem apontado para a existência de um processo de reestruturação industrial no setor de papel e celulose em nível internacional, sobretudo, nos países da América do Norte (EUA e Canadá) compreendendo: maior internacionalização do setor e liberalização dos mercados, mudanças na propriedade do capital, reorganização do trabalho, redução dos custos de produção por meio de automatização da produção, desenvolvimento da polivalência e da flexibilidade dos trabalhadores, redução do volume do emprego através de modernização de equipamentos industriais e de reorganização do trabalho.

Esse movimento internacional de reestruturação que repercute na indústria brasileira de celulose de mercado, afetando diretamente os trabalhadores aí localizados, é marcado pelo aprofundamento no caráter da divisão internacional do trabalho, mudanças na propriedade e na composição acionária das empresas, as ameaças de transferência geográfica de plantas e de elos e/ou etapas da cadeia produtiva, hierarquização e especialização da produção, fusões e aquisições patrimoniais e concentração do capital. A intensidade com que este processo se verifica neste ramo da indústria pode estar relacionada ao seu elevado grau de exposição à economia mundial e ao comércio internacional. O movimento de reestruturação compreende um conjunto de mudanças no padrão tecnológico, na organização da produção, na relação entre empresas, nas políticas de gestão da mão-de-obra, na relação com a comunidade local e na organização dos sindicatos de trabalhadores, que ocorre simultaneamente a um processo de articulação internacional das entidades sindicais dos trabalhadores papeleiros.

A questão que orienta este artigo refere-se aos efeitos do processo de globalização e de reestruturação produtiva para o tipo de trabalhador tradicionalmente encontrado nas indústrias de processo contínuo de bens dimensionais, sobretudo, aquelas expostas ao comércio internacional. Em geral, esse trabalhador caracteriza-se por ser homem, branco, dotado de elevado nível de escolarização em relação à média dos trabalhadores industriais, qualificado, portador de anos de experiência numa mesma fábrica (denominado operador 'casado' com a planta), cujo conteúdo do trabalho distingue-se por ser intelectualmente complexo e remunerado com salários mais elevados que a média dos trabalhadores brasileiros e protegido por um conjunto de benefícios e direitos sociais.

Portanto, que transformações decorrentes da introdução de novas tecnologias de produção, de novas formas de organizar o trabalho e de modernas políticas de gestão de recursos humanos podem ainda ter lugar num tipo de indústria, como a de processo contínuo, que sempre foi considerada a 'vanguarda' do ramo industrial?

Com a globalização tem lugar um processo de alteração e (re)estruturação das relações de poder não apenas entre países e no interior das cadeias produtivas, mas também no interior das fábricas e nos distintos locais de trabalho, modificando as relações de força entre os diversos atores envolvidos na produção, e tendo na participação da mão-de-obra uma relevante mediadora.

Esta mudança nas relações de força está intimamente relacionada à sofisticação das formas de obter controle, disciplina e consentimento. Neste sentido, o engajamento dos trabaIhadores ao processo de reestruturação das empresas pesquisadas não se explica, apenas, por uma lógica coercitiva/compulsória cuja moeda de troca é o emprego. Sendo relevante considerar 
uma lógica simbólica/relacional como amálgama das relações estabelecidas entre empresa e trabalhadores, que também é utilizada para sedimentar as novas práticas de produção e de gestão, bem como para questionar a legitimidade das entidades sindicais em presença.

Estas duas lógicas (coercitiva/simbólica) se articulam da seguinte forma. Por um lado, no plano da dimensão coercitiva, em nome da competitividade e do acirramento da concorrência, verificam-se alterações unilaterais na gestão das empresas, na organização da produção e do trabalho e nas políticas de gestão de mão-de-obra. Estas modificações têm conseqüências diretas para os trabalhadores compreendendo redução do volume do emprego, alterações no perfil da mão-de-obra sobrevivente, intensificação do trabalho, imposição de requisitos mais elevados para contratação e permanência na empresa, exigência de um novo padrão de comportamento dos trabalhadores, flexibilização de direitos trabalhistas, etc.

Por outro lado, no plano da dimensão simbólica, as empresas buscam reelaborar a sua representação no imaginário dos trabalhadores a partir da difusão de um discurso pedagógico enriquecido por referências éticas, morais, cívicas, de compromissos e responsabilidades sociais, de comprometimento com os seus valores, os quais deverão ser apreendidos e incorporados à visão de mundo dos trabalhadores. É neste campo relacional, no qual se fertilizam as emoções, as lembranças de uma vida e das conquistas possibilitadas por intermédio do vínculo com as empresas (a compra do carro, o financiamento da casa própria, o casamento, a formatura dos filhos, o curso de línguas, o plano de saúde, o acesso ao clube, os passeios de férias ou as viagens a trabalho, a aposentadoria privada, etc.) e o processo de identificação entre as empresas e seus trabalhadores, que as relações de força e de exploração são metamorfoseadas e as contradições dissimuladas, obscurecendo os constrangimentos e as arbitrariedades presentes na lógica coercitiva. A reconstrução da imagem das empresas e a incorporação dos trabalhadores adubam, deste modo, o terreno afetivo para reforçar o envolvimento dos trabalhadores, cultivar a sua participação e obter a sua adesão à lógica competitiva das estratégias gerenciais.

Neste contexto, a comunicação das empresas com os trabalhadores é um dos aspectos centrais do processo de reestruturação produtiva em curso nas empresas pesquisadas. Constitui instrumento útil tanto para divulgar as mudanças no plano da gestão e os novos comportamentos requeridos pelas empresas, quanto para (re)trabalhar e fixar a representação simbólica das empresas no imaginário dos trabalhadores e/ou interferir nas representações mentais que os trabalhadores constroem sobre elas.

Desta maneira, é possível identificar um processo de reestruturação de forma, conteúdo e veículos de comunicação com os trabalhadores e suas famílias. A comunicação passa a ser encarada como um elemento significativo da estratégia corporativa e como um instrumento de mediação e apoio no relacionamento entre empresas, trabalhadores, famílias e prestadores de serviço, bem como de difusão da imagem de 'empresas-cidadãs' e, ao mesmo tempo, de sucesso: exemplo a ser seguido pelos empregados. Garante a produção de corpos e mentes afinados com os discursos e as estratégias das empresas num contexto em que se aprofunda a sua inserção na economia internacional. Embora seja possível pensar em resistências: pontuais (nem sempre verbalizadas publicamente pelos trabalhadores) ou coletivas (através da ação sindical), mas que não chegam a invalidar o clima geral de engajamento.

A difusão e o compartilhamento de informações com os trabalhadores da produção é um elemento crucial do processo de reestruturação nas empresas pesquisadas. Por um lado, o compartilhamento dessas informações, que se concentravam nos níveis hierárquicos superiores, tornou-se possível graças à mediação das novas tecnologias (informática e microeletrônica), mas também se deveu a certo interesse político das gerências em compartilhá-las com os trabalhadores. $O$ fato 
de disponibilizar a informação outrora monopólio e prerrogativa das chefias, reforça, ainda, a dimensão simbólica presente no discurso das empresas, enfatizando a relação de confiança que as mesmas depositam nos trabalhadores, de modo a obter sua cumplicidade com os objetivos das empresas dentro e/ou fora da fábrica e construir o consentimento para as mudanças.

Este trabalho está dividido em quatro seções, além desta introdução e da conclusão. $\mathrm{Na}$ próxima seção será apresentada a estratégia de pesquisa utilizada para a realização da pesquisa. A seção 3 trata das transformações mundiais no setor de papel e celulose e suas conseqüências para as empresas brasileiras que integram o segmento de celulose de mercado (market pulp). Por fim, a relação entre o ajuste realizado no mercado de trabalho e as estratégias gerenciais das empresas, assim como os atributos que permitiram a continuidade dos trabalhadores em seus postos de trabalho serão tratadas na seção 4.

\section{METODOLOGIA}

Trata-se de um estudo de caso exploratório, cujo objetivo é elucidar e aprofundar a compreensão do fenômeno estudado em situações particulares, por meio da coleta, análise e interpretação de uma variedade de evidências: pesquisa bibliográfica, pesquisa de campo, pesquisa documental e análise de estatísticas sobre o mercado de trabalho disponível nas bases de dados da Relação Anual de Informações Sociais do Ministério do Trabalho e Emprego (RAIS/MTE). Destaca-se o caráter qualitativo do estudo, já que nenhuma amostragem científica foi inferida e não há tentativas de quantificar os resultados obtidos. Ao contrário, um pequeno grupo de respondentes está comprometido com a idoneidade e com a precisão da investigação (VASCONCELLOS, 2008; YIN, 2001).

As seis (6) empresas escolhidas como objetos da investigação integram o subgrupo $\mathrm{Ce}$ lulose e Outras Pastas para Fabricação (celulose de mercado ou market pulp), segundo classificação utilizada pela Relação Anual de Informações Sociais do Ministério do Trabalho e Emprego (RAIS/MTE). Foram empresas escolhidas dadas ao tipo de produto que fornecem aos seus compradores, a posição que ocupam na cadeia produtiva, a vocação competitiva (mercado externo ou doméstico), as mudanças na propriedade do capital e a localização. O quadro a seguir sintetiza as características gerais das seis empresas pesquisadas no período 2000 a 2005 :

Quadro 1 - Caracterização das empresas estudadas no segmento de celulose de mercado

\begin{tabular}{|c|c|c|c|c|c|c|}
\hline Empresas & $\begin{array}{c}\text { Aracruz/ } \\
\text { Fibria S/A }\end{array}$ & Lwarcel Ltda. & $\begin{array}{c}\text { Riocell / Celu- } \\
\text { lose Riogran- } \\
\text { dense S/A }\end{array}$ & Cenibra S/A & Jari S/A & VCP-JAC S/A \\
\hline $\begin{array}{l}\text { Origem do } \\
\text { capital na } \\
\text { fundação }\end{array}$ & $\begin{array}{c}\text { Nacional } \\
\text { (BNDES); } \\
\text { Norueguesa } \\
\text { (Lorentzen); } \\
\text { Finlandesa } \\
\text { (Bilerud) }\end{array}$ & $\begin{array}{c}\text { Nacional } \\
\text { (família Tre- } \\
\text { centi) }\end{array}$ & $\begin{array}{l}\text { Norueguesa } \\
\text { (Grupo Borre- } \\
\text { gaard) }\end{array}$ & $\begin{array}{c}\text { Nacional } \\
\text { (CVRD) e Ja- } \\
\text { ponesa (Japan } \\
\text { Brazil Paper) }\end{array}$ & $\begin{array}{c}\text { Norte-ameri- } \\
\text { cana (Univer- } \\
\text { se Tankships } \\
\text { Inc); Nacional } \\
\text { (Grupo Cae- } \\
\text { mi, Banco do } \\
\text { Brasil e BN- } \\
\text { DES) }\end{array}$ & $\begin{array}{l}\text { Libanesa (Ir- } \\
\text { mãos Simão } \\
\text { Racy) }\end{array}$ \\
\hline $\begin{array}{c}\text { Ano de } \\
\text { fundação }\end{array}$ & 1972 & 1985 & 1967 & 1973 & $\begin{array}{l}1967 \\
\text { (sob o con- } \\
\text { trole de Da- } \\
\text { niel Ludwig) }\end{array}$ & $\begin{array}{c}1992 \\
\text { (sob o Grupo } \\
\text { Votorantim) }\end{array}$ \\
\hline $\begin{array}{l}\text { Início das } \\
\text { operações } \\
\end{array}$ & 1978 & 1986 & 1972 & 1977 & 1979 & 1992 \\
\hline Localização & $\begin{array}{c}\text { Aracruz } \\
\text { (ES) }\end{array}$ & $\begin{array}{c}\text { Lençóis Pau- } \\
\text { lista (SP) }\end{array}$ & $\begin{array}{c}\text { Guaíba } \\
\text { (RS) }\end{array}$ & $\begin{array}{l}\text { Belo Oriente } \\
\text { (MG) }\end{array}$ & $\begin{array}{l}\text { Monte Dou- } \\
\text { rado (PA) }\end{array}$ & $\begin{array}{c}\text { Jacareí } \\
\text { (SP) }\end{array}$ \\
\hline
\end{tabular}


GLICIA VIEIRA DOS SANTOS,

ANGELA MARIA CARNEIRO ARAÚJO E

LEDA MARIA CAIRA GITAHY

\begin{tabular}{|c|c|c|c|c|c|c|}
\hline Empresas & $\begin{array}{c}\text { Aracruz/ } \\
\text { Fibria S/A }\end{array}$ & Lwarcel Ltda. & $\begin{array}{c}\text { Riocell / Celu- } \\
\text { lose Riogran- } \\
\text { dense S/A }\end{array}$ & Cenibra S/A & Jari S/A & VCP-JAC S/A \\
\hline $\begin{array}{c}\text { Tipo de } \\
\text { produto }\end{array}$ & $\begin{array}{c}\text { Celulose de } \\
\text { mercado }\end{array}$ & $\begin{array}{c}\text { Celulose de } \\
\text { mercado, } \\
\text { sisal, abacá } \\
\text { e fluff }\end{array}$ & $\begin{array}{c}\text { Celulose de } \\
\text { mercado e } \\
\text { papel }\end{array}$ & $\begin{array}{c}\text { Celulose de } \\
\text { mercado }\end{array}$ & $\begin{array}{c}\text { Celulose de } \\
\text { mercado }\end{array}$ & $\begin{array}{c}\text { Celulose de } \\
\text { mercado e } \\
\text { papel }\end{array}$ \\
\hline $\begin{array}{c}\text { Mercado } \\
\text { de atuação } \\
\text { América } \\
\text { do Norte } \\
(36 \%) ; \\
\text { Ásia (23\%); } \\
\text { América La- } \\
\text { tina (3\%) }\end{array}$ & $\begin{array}{c}\text { Europa (5\%); } \\
\text { Mercado in- }\end{array}$ & $\begin{array}{c}\text { Mercado } \\
\text { externo }\end{array}$ & $\begin{array}{c}\text { Japão (41\%), } \\
\text { Europa } \\
(30 \%), \\
\text { Estados Uni- } \\
\text { dos (16\%) }\end{array}$ & $\begin{array}{c}\text { Europa } \\
(59 \%), \text { Ásia } \\
(21 \%), \text { Amé- } \\
\text { rica Latina } \\
(12 \%) \text { e Amé- } \\
\text { rica do Norte } \\
(8 \%)\end{array}$ & $\begin{array}{c}\text { Europa } \\
(45 \%), \text { Ásia } \\
(16 \%)\end{array}$ \\
\hline $\begin{array}{c}\text { Posição na } \\
\text { cadeia }\end{array}$ & Fornecedor \\
\hline
\end{tabular}

Fonte: Elaboração própria.

Foram realizadas visitas às unidades industriais, além de entrevistas gravadas e não gravadas com uma amostra intencional de: trabalhadores(as) da produção, técnicos de manutenção, trabalhador(a)s administrativo(a)s, diretores, gerentes, supervisores, coordenadores e assistentes técnicos, trabalhadores e representantes de empresas terceirizadas, dirigentes e advogados sindicais, conforme quadro a seguir.

Quadro 2 - Total de entrevistas realizadas no período 2001-2004

\begin{tabular}{|c|c|c|c|}
\hline \multicolumn{2}{|r|}{ Amostra } & Entrevistas gravadas & Entrevistas não-gravadas \\
\hline \multirow[t]{9}{*}{ Empresas } & Aracruz Celulose/Fibria (ES) & 3 & 17 \\
\hline & Riocell (RS) & 16 & 8 \\
\hline & Cenibra (MG) & 20 & 15 \\
\hline & Jari Celulose (PA) & 30 & 19 \\
\hline & Lwarcel Celulose e Papel (SP) & 18 & 3 \\
\hline & Votorantim-Jacareí (SP) & - & 15 \\
\hline & Votorantim-Luís Antônio (SP) & 22 & 11 \\
\hline & Cascades Inc. (Québec, Qc) & - & 25 \\
\hline & Papier Stadaconna (Québec, Qc) & - & 12 \\
\hline \multirow{6}{*}{$\begin{array}{l}\text { Entidades } \\
\text { Sindicais }\end{array}$} & SINAP (SP) & 1 & 2 \\
\hline & SINTRACEL (PA) & 1 & - \\
\hline & SINDGUAÍBA (RS) & 1 & - \\
\hline & SINTICEL (MG) & - & 1 \\
\hline & SINTICEL (ES) & - & 2 \\
\hline & SCEP (Québec, Qc) & - & 1 \\
\hline \multirow{7}{*}{$\begin{array}{c}\text { Empresas } \\
\text { subcontrata- } \\
\text { das }^{4}\end{array}$} & Sindus (PA) & 1 & - \\
\hline & Cegelec (PA) & 1 & - \\
\hline & $\mathrm{ABB}(\mathrm{SP})$ & 1 & - \\
\hline & Suporte (SP) & 1 & - \\
\hline & Dalkia Infra 4 (SP) & 1 & - \\
\hline & Lubiani Transportes (SP) & 1 & - \\
\hline & Prestador de serviço autônomo & 1 & - \\
\hline \multicolumn{2}{|r|}{ Total } & 119 & 131 \\
\hline
\end{tabular}

Fonte: Elaboração própria.

4 Sindus, Celegec e ABB: serviços de manutenção industrial (instrumentação, elétrica e mecânica). Suporte: serviços de movimentação de estoques e produtos acabados. Dalkia Infra 4: serviços de gerenciamento de contratos de terceiros. Lubiani: transporte e distribuição de produtos acabados. 0 prestador de serviço autônomo prestava serviços de consultoria em montagem e projetos na área industrial. 
Os roteiros de entrevista nortearam-se basicamente pelas seguintes questões: caracterização das empresas, tecnologia e organização do trabalho com ênfase em inovações tecnológicas e organizacionais, perfil da força-de-trabalho, condições de trabalho e emprego, políticas de gestão da mão-de-obra (treinamentos, benefícios, carreiras, remuneração, etc.), requisitos de qualificação, relações com os sindicatos e vice-versa, relações com a comunidade local.

A pesquisa documental foi baseada na coleta de informações na mídia impressa, televisada e eletrônica (recortes de jornais, jornais internos das empresas, livros, revistas, vídeos e sites de internet). Foram realizados monitoramentos periódicos nas principais páginas eletrônicas nacionais, internacionais, governamentais, de organizações (não governamentais, de formação profissional, de pesquisa, entidades sindicais), e de associações relacionadas ao setor de celulose e papel. Desta forma, um conjunto de informações do setor de celulose e papel foi reunido e lido visando a informar a análise sobre a realidade setorial. Além disso, foi realizado um levantamento de dados adicionais na biblioteca da Associação Brasileira de Celulose e Papel (BRACELPA), com o objetivo de realizar um inventário bibliográfico de toda a literatura empresarial, governamental, setorial e acadêmica produzida sobre este setor. Quando foi o caso, também foram visitadas as bibliotecas das empresas pesquisadas no período do trabalho de campo (Aracruz Celulose/Fibria S/A, Cenibra S/A e Jarí Celulose S/A).

Como atividade complementar ao trabalho de campo realizado no Brasil, foram realizadas visitas e entrevistas com representantes do Syndicat canadien des communications, de l'énergie et du papier (SCEP) em Montréal. Tal entidade representa 150 mil trabalhadores dos setores de papel e celulose, petroleiro, gás, químico, exploração mineral e de telefonia. Também foram visitadas duas empresas québécoises produtoras de papel e papelão, quais sejam: Cascades Inc. no município de Kingsey Falls e Papier Stadacona na cidade de Québec 5 .

Desta forma, pretendeu-se combinar na análise tanto a dimensão qualitativa e comparativa entre os processos de reestruturação produtiva, levados a cabo nas empresas integrantes da amostra considerada, quanto uma visão pluridimensional do processo de reestruturação produtiva por meio da perspectiva e dos discursos dos diversos sujeitos do processo de trabalho, além da análise de dados quantitativos sobre o setor e de estatísticas oficiais sobre o mercado de trabalho.

\section{A GLOBALIZAÇÃO E A REESTRUTURAÇÃO SISTÊMICA DO SETOR PAPELEIRO}

O movimento internacional de redefinição das estratégias gerenciais das empresas combinado com a emergência e a difusão de novas formas de organização da produção e do trabalho no setor de papel e celulose repercutiu-se no segmento brasileiro de celulose de mercado, convivendo ao mesmo tempo, no início dos anos 90, com um contexto particular de mudanças sociais, econômicas e políticas que se disseminavam no Brasil por meio da abertura econômica, da privatização de empresas estatais e da consolidação da democracia política.

Em geral, as novas formas de organização industrial no setor estão assentadas na informatização da produção, na redução do patrimônio das empresas, na flexibilidade, na introdução de programas de qualidade, na diferenciação de produtos, na redução dos efetivos administrativo e fabril, na reorganização do trabalho e na participação dos trabalhadores (Lapointe, 2000-a). Assiste-se, de igual modo, à redefinição do padrão de relacionamento das empresas com sua mão-de-obra, as firmas e o Estado, tendo na produção de novas formas de consentimento dos trabalhadores, um de seus principais eixos de sustentação (Guimarães, 2004).

5 Trata-se de uma atividade complementar ao trabalho principal, não sendo intenção deste artigo, entretanto, realizar um estudo comparativo na perspectiva Brasil-Canadá. 
Tanto as empresas dos países centrais que ocupam a liderança e coordenam a cadeia produtiva internacional, quanto aquelas oriundas dos países periféricos têm sofrido, em graus e ritmos específicos, os efeitos da emergência dessas transformações ao longo da cadeia produtiva do setor de papel e celulose. Apenas para dimensionar a extensão das alterações que afetam tanto as empresas representantes dos países líderes, quanto as dos países periféricos desta cadeia produtiva, é relevante mencionar que, nos anos 90 , também a indústria canadense de papel e celulose passou por transformações significativas.

O primeiro aspecto que merece atenção foi a perda de sua competitividade com a aparição de novos produtores americanos dispondo de custos de produção mais reduzidos, devido ao uso de novas tecnologias e matérias-primas (Lapointe, 2000-a). Apesar da sua vantagem competitiva baseada na abundância e na proximidade das florestas de espécies coníferas, por muito tempo as empresas canadenses desse setor deixaram de investir na introdução de novas tecnologias e equipamentos de produção. Deste modo, ao mesmo tempo em que elas se encontravam com um parque industrial tecnologicamente obsoleto num contexto de acirramento da concorrência e de elevação das exigências ambientais, as empresas tiveram que melhorar seus equipamentos de produção e de transporte de madeira.

Além disso, foram realizados neste mesmo período diversos movimentos de fusão, de desagregação de oligopólios, de especialização de produtores e de expansão das empresas canadenses independentes. Lapointe (2000-a) observa que o processo de reestruturação da indústria canadense de papel e celulose foi acompanhado de uma redução significativa do emprego total no setor, no período de 1989 a 1995, da ordem de 30\%.

Um processo de transformações semelhante foi verificado em diferentes setores da atividade industrial de fluxo contínuo. Guimarães (2004), por exemplo, ao analisar o processo de reestruturação produtiva nas químico-petroquímicas brasileiras, observa que para além da reestruturação 'conservadora' e 'para dentro' que teve lugar nos anos 80 , cujo foco central das estratégias de negócios das empresas era a redução de custos -; a reestruturação nos anos 90 assumiu um caráter 'sistêmico' com as estratégias de negócios tendo um escopo ampliado. Isto é, constituem alterações sistêmicas, porque alcançaram desde a estruturação das cadeias (fusões e aquisições, incorporações, cisões, mudanças na propriedade do capital, alianças estratégias, desativação de unidades produtivas, especializações em ramos completos, redirecionamento de negócios, etc.), passando pelas estratégias de mercado e de controle de custos, pela reestruturação organizacional e tecnológica, até às estratégias de gestão de recursos humanos e regulação das relações de trabalho. Além disso, a autora destaca o efeito multiplicador dessas transformações que ultrapassaram o interior das empresas líderes, expandindo-se 'para fora', isto é, ao longo da cadeia produtiva. Daí o termo 'sistêmico' cunhado e atribuído por Guimarães (2004) a tais transformações, dado seu desdobramento em dimensões que extrapolam o limite interno das empresas, gerando efeitos em cascata ou reação em cadeia, como numa queda de dominós.

Esta mudança qualitativa no processo de reestruturação também foi verificada na indústria brasileira de papel e celulose e, em especial, no segmento de celulose de mercado. A inserção desta indústria na cadeia produtiva global desde os anos 60 , e sua integração ao mercado internacional mais fortemente a partir dos anos 90 , implicou a redefinição das estratégias gerenciais das empresas e a adoção de um conjunto de medidas sistêmicas relacionadas com as novas formas de organização industrial.

Nas empresas brasileiras investigadas as novas estratégias gerenciais combinaram a introdução de programas relativos à gestão do patrimônio e do investimento, à gestão da empresa, à gestão da produção e da qualidade, à gestão de recursos humanos, à reorganização do processo 
de trabalho, à implantação de dispositivos participativos da mão-de-obra, à terceirização de atividades e serviços, e, à atuação social na comunidade local tanto por parte das empresas, quanto por parte dos seus trabalhadores e prestadores de serviço.

Desta maneira, nas empresas estudadas, foram modernizadas as instalações florestais, industriais e logísticas com a finalidade de elevar escalas de produção, suprindo os déficits internacionais relacionados ao aumento no consumo de fibras e ao crescimento do consumo de papéis. Entretanto, é necessário enfatizar que a ampliação das escalas de produção e o crescimento da produtividade não foram garantidos apenas com a modernização tecnológica das instalações fabris e diminuição do volume de empregos diretos. O engajamento psíquico, intelectual e físico dos trabalhadores constitui elemento fundamental para potencializar o máximo rendimento global das modernas instalações e conquistar com uma eficácia extraordinária os padrões de eficiência de produção, de qualidade, de redução de custos e o desempenho ambiental aspirado pelas empresas e divulgado sob o estatuto de 'recordes' diários, mensais e anuais de produção freqüentemente alcançados.

Daí o estabelecimento de políticas de gestão da mão-de-obra que combinam a participação da força-de-trabalho, a transferência de autonomia e responsabilidade aos trabalhadores, a valorização da segurança no trabalho (individual, coletiva e de equipamentos), o treinamento e o desenvolvimento da mão-de-obra, além de políticas de distribuição de contrapartidas materiais e simbólicas. Sendo também importante considerar a difusão e o compartilhamento de informações relativas à produção e o investimento em comunicação com os trabalhadores como elementos centrais do processo de reestruturação das empresas. Este investimento que se traduz, sobretudo, no sentido de 'gastar tempo' explicando as mudanças e ouvindo os subordinados, constitui um poderoso instrumento para conquistar a adesão, construir o consentimento e capitanear uma maior mobilização tanto dos trabalhadores, quanto dos representantes dos demais níveis hierárquicos, em favor das estratégias de mercado de suas empresas.

Assim, é possível apontar para a difusão de um conjunto de inovações tecnológicas e gerenciais que se reproduzem, em graus e ritmos distintos, nas empresas que integram o segmento brasileiro de celulose de mercado. Alinhado às estratégias de negócios das empresas, este corpus de inovações obedece a uma lógica e a uma coerência interna que, segundo Bélanger (2000), combina inovações complementares e integradas, tanto no plano da tecnologia, quanto no plano da organização e da gestão do trabalho.

Neste sentido, a reestruturação que tem lugar nesta indústria, a partir da segunda metade dos anos 90, caracteriza-se por ser 'sistêmica'6 isto é, para além do controle de custos como um fim em si mesmo, as estratégias de negócios passaram a ter uma maior abrangência, implicando a redefinição das estratégias gerenciais internas às empresas. Ademais, essas transformações transbordaram e se estenderam 'para fora' das empresas, isto é, ao longo da cadeia produtiva de produtores e distribuidores, modificando as relações entre as firmas? ${ }^{7}$.

\section{OS AJUSTES NO MERCADO DE TRABALHO E AS MU- DANÇAS NA ORGANIZAÇÃO DO TRABALHO E NAS PO- LIITICAS DE PESSOAL}

Diante do ritmo e do alcance das mudanças até aqui elucidadas cabem algumas indagações relativas ao ajuste ocorrido no mercado de trabalho brasileiro, sua relação com as estratégias de negócios das empresas e os efeitos conexos para os trabalhadores remanescentes.

\footnotetext{
6 Termo cunhado por Guimarães (2004) para designar um conjunto de transformações internas e externas às empresas, com impactos em toda a cadeia produtiva.

7 Ver Guimarães (2004).
} 
Neste sentido, quais foram os sobreviventes ao ajuste realizado pelas empresas e que atributos funcionaram como credenciais permitindo a exclusão ou a permanência dos trabalhadores em seus postos de trabalho? Que tipo de inserção e em que postos de trabalho permaneceram as trabalhadoras e os trabalhadores remanescentes? Em que medida as alterações no mercado de trabalho interno às empresas e na divisão sexual do trabalho comporta uma perspectiva que pode ser influenciada tanto pelo conteúdo das estratégias de gestão das empresas, quanto pelas características adscritivas de sua mão-de-obra (sexo e idade), podendo estas últimas prevalecer sobre a qualificação formal e as qualidades adquiridas (escolaridade e tempo de serviço) da força-de-trabaIho, reforçando as assimetrias entre homens e mulheres na esfera da produção?

Para elucidar tais questões utilizou-se como ferramenta a tabulação das informações contidas na base de dados da Relação Anual de Indicadores Sociais do Ministério do Trabalho e Emprego (RAIS/MTE). Para tanto, foram selecionadas variáveis aquisitivas (ocupação, escolaridade e tempo de serviço) e adscritivas (idade e sexo). $O$ objetivo da análise desses dados consiste em identificar, a partir de indicadores que realçam a dinâmica do mercado de trabalho: 1 . a evolução da estrutura do emprego no segmento de Celulose e Outras Pastas para Fabricação (celulose de mercado) num intervalo temporal de quase 10 anos, de 1994 a 2002, período marcado pelo início e aprofundamento do processo de reestruturação produtiva neste segmento; 2 . quais as estratégias de gestão da mão-de-obra utilizadas pelas empresas; e, 3 quais foram os trabalhadores 'sobreviventes' ao ajuste realizado no período e que 'credenciais' endossaram a sua permanência nas empresas.

Assim, analisando os indicadores do mercado brasileiro de trabalho para o período de início e aprofundamento da reestruturação (de 1994 a 2002) no setor industrial considerado, constata-se que, em primeiro lugar, o sexo colaborou como demarcador das oportunidades de emprego para as mulheres, ou seja, funcionou como credencial para definir a contratação e a permanência, sobretudo, nas atividades ditas 'femininas' (viveiro, conservação e limpeza, recepção, etc.). Todavia, por outro lado, com a mudança tecnológica na produção e a maior informatização das áreas administrativas, as mulheres também perderam postos de trabalho no chão-de-fábrica e, principalmente, nos escritórios (nos quais historicamente sempre formaram a maioria) onde, em contrapartida, os homens aumentaram a sua participação.

Tabela 1 - Distribuição percentual do volume do emprego feminino por ocupação, Brasil

\begin{tabular}{|c|c|c|c|c|c|c|c|c|c|c|}
\hline & & \multicolumn{9}{|c|}{ Anos } \\
\hline Grupo & Descrição das ocupações & 1994 & 1995 & 1996 & 1997 & 1998 & 1999 & 2000 & 2001 & 2002 \\
\hline GRUPO 01 & Químicos e Físicos & 0,0 & 0,1 & 0,0 & 0,0 & 0,0 & 0,0 & 0,0 & 0,0 & 1,5 \\
\hline GRUPO 02 & Engenheiros & 1,2 & 1,6 & 0,6 & 1,3 & 1,7 & 2,0 & 1,9 & 2,4 & 2,9 \\
\hline GRUPO 03 & Técnicos & 4,8 & 5,7 & 6,4 & 6,8 & 10,5 & 9,5 & 10,4 & 11,4 & 9,8 \\
\hline $\begin{array}{c}\text { GRUPO } 04 \\
\text { a } 19\end{array}$ & Outros Profissionais & 9,4 & 13,5 & 10,9 & 9,2 & 14,8 & 12,7 & 12,5 & 13,6 & 15,4 \\
\hline GRUPO 23 & Diretores & 0,0 & 0,0 & 0,3 & 0,1 & 0,1 & 0,1 & 0,2 & 0,1 & 0,0 \\
\hline GRUPO 24 & Gerentes & 1,7 & 3,7 & 4,4 & 1,4 & 1,9 & 1,7 & 2,1 & 1,8 & 1,6 \\
\hline $\begin{array}{c}\text { GRUPO } 30 \\
\text { a } 40\end{array}$ & Equipe Administrativa & 39,3 & 47,1 & 43,3 & 39,4 & 42,4 & 39,0 & 38,7 & 34,4 & 37,9 \\
\hline GRUPO 50 & $\begin{array}{c}\text { Conservação e Segurança } \\
\text { Patrimonial }\end{array}$ & 3,4 & 4,5 & 5,0 & 5,4 & 4,7 & 4,7 & 3,9 & 3,1 & 3,4 \\
\hline GRUPO 60 & Trabalhadores da Floresta & 4,5 & 0,5 & 3,6 & 3,7 & 5,3 & 7,8 & 4,7 & 5,1 & 8,2 \\
\hline $\begin{array}{c}\text { GRUPO } 70 \\
\text { a } 90\end{array}$ & Trabalhadores da Fábrica & 35,7 & 23,5 & 25,6 & 32,6 & 18,4 & 22,5 & 25,6 & 27,9 & 19,4 \\
\hline \multirow[t]{2}{*}{ IGNORADO } & Ignorado & 0,0 & 0,0 & 0,0 & 0,0 & 0,1 & 0,0 & 0,0 & 0,0 & 0,0 \\
\hline & Total & 100,0 & 100, & 100,0 & 100,0 & 100,0 & 100,0 & 100,0 & 100,0 & 100,0 \\
\hline
\end{tabular}

Fonte: Elaboração a partir da base de dados da RAIS/ MTE. 
TRABALHO, TECNOLOGIA E INOVAÇÃO NA INDÚSTRIA DE PROCESSO CONTÍNUO:

AS TRANSFORMAÇÕES NA INDÚSTRIA BRASILEIRA DE CELULOSE DE MERCADO

Tabela 2 - Distribuição percentual do volume do emprego masculino por ocupação, Brasil

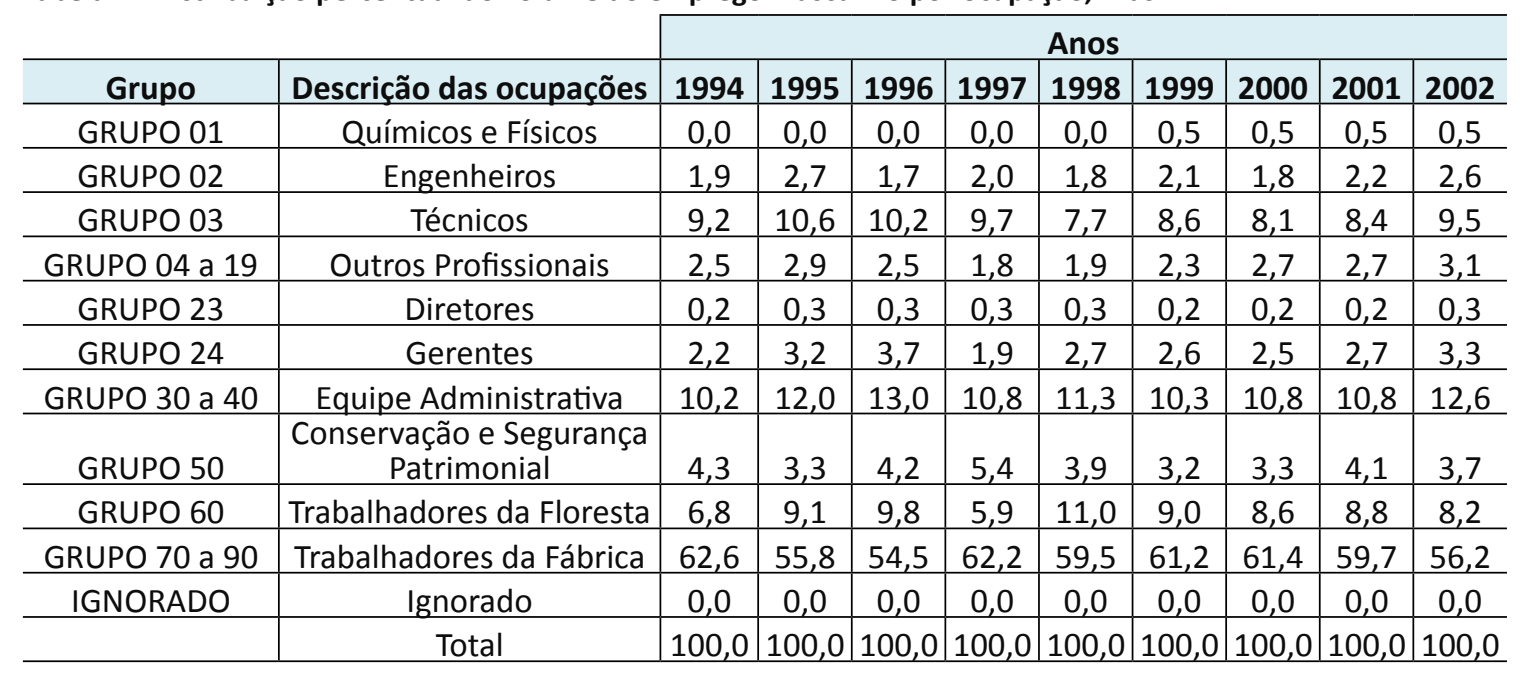

Fonte: Elaboração a partir da base de dados da RAIS/ MTE.

Em segundo lugar, a idade funcionou como parâmetro para definir a permanência, a seleção e a demissão de trabalhadoras e trabalhadores. Dada a natureza desse tipo de indústria em que a experiência é considerada um elemento vital para a produção, foi possível constatar pela maior concentração do volume de mão-de-obra nas faixas etárias mais elevadas, que a preferência das empresas - tanto para contratação quanto para permanência no emprego - recaiu sobre os trabalhadores e trabalhadoras mais maduros (30 anos ou mais).

Tabela 3 - Distribuição percentual do volume do emprego por sexo e idade, Brasil

\begin{tabular}{c|c|c|c|c|c|c|c|c|c}
\cline { 2 - 9 } Masculino & \multicolumn{10}{c}{ Anos } \\
\cline { 2 - 10 } & $\mathbf{1 9 9 4}$ & $\mathbf{1 9 9 5}$ & $\mathbf{1 9 9 6}$ & $\mathbf{1 9 9 7}$ & $\mathbf{1 9 9 8}$ & $\mathbf{1 9 9 9}$ & $\mathbf{2 0 0 0}$ & $\mathbf{2 0 0 1}$ & $\mathbf{2 0 0 2}$ \\
\hline Até 17 anos & 1,7 & 1,2 & 1,1 & 0,9 & 0,8 & 0,8 & 0,8 & 0,5 & 0,5 \\
\hline 18 a 29 anos & 34,3 & 32,7 & 33,1 & 32,2 & 26,9 & 27,4 & 27,8 & 27,7 & 26,2 \\
\hline 30 a 39 Anos & 37,7 & 38,2 & 38,8 & 38,7 & 40,4 & 40,6 & 39,5 & 38,8 & 37,7 \\
\hline 40 a 49 Anos & 20,1 & 21,9 & 21,0 & 22,0 & 24,4 & 24,5 & 24,8 & 25,3 & 26,8 \\
\hline 50 a 64 Anos & 5,9 & 5,6 & 5,7 & 5,8 & 7,0 & 6,4 & 6,8 & 7,4 & 8,5 \\
\hline 65 Anos ou Mais & 0,3 & 0,3 & 0,3 & 0,4 & 0,4 & 0,3 & 0,3 & 0,3 & 0,3 \\
\hline Ignorado & 0,1 & 0,0 & 0,0 & 0,0 & 0,0 & 0,0 & 0,0 & 0,0 & 0,0 \\
\hline Total & 100,0 & 100,0 & 100,0 & 100,0 & 100,0 & 100,0 & 100,0 & 100,0 & 100,0 \\
\hline
\end{tabular}

Feminino

\begin{tabular}{c|c|c|c|c|c|c|c|c|c}
\hline Até 17 Anos & 3,4 & 2,2 & 1,7 & 1,4 & 1,3 & 1,0 & 1,3 & 1,4 & 0,9 \\
\hline 18 a 29 Anos & 44,8 & 41,1 & 41,2 & 40,8 & 32,7 & 32,6 & 34,1 & 34,7 & 35,4 \\
\hline 30 a 39 Anos & 36,1 & 38,5 & 38,3 & 38,6 & 43,1 & 43,1 & 41,7 & 40,3 & 37,0 \\
\hline 40 a 49 Anos & 13,7 & 15,2 & 15,8 & 15,6 & 19,1 & 19,1 & 19,1 & 19,8 & 21,7 \\
\hline 50 64 Anos & 2,1 & 2,9 & 2,9 & 3,5 & 3,6 & 4,1 & 3,7 & 3,7 & 4,8 \\
\hline 65 Anos ou Mais & 0,0 & 0,1 & 0,1 & 0,1 & 0,1 & 0,1 & 0,1 & 0,1 & 0,2 \\
\hline Ignorado & 0,0 & 0,0 & 0,0 & 0,0 & 0,0 & 0,0 & 0,0 & 0,0 & 0,0 \\
\hline Total & 100,0 & 100,0 & 100,0 & 100,0 & 100,0 & 100,0 & 100,0 & 100,0 & 100,0 \\
\hline
\end{tabular}

Fonte: Elaboração a partir da base de dados da RAIS/MTE.

Em terceiro lugar, a escolaridade e o tempo de serviço foram variáveis que não atuaram isoladamente, mas se imbricaram enquanto atributos demarcadores das chances de permanência no emprego e de contratação da mão-de-obra. Isto é, a baixa escolaridade não contribuiu como critério para excluir os trabalhadores com maior tempo de casa e, por suposto, mais experientes. Mas funcionou, por outro lado, como credencial para excluir os trabalhadores com 
menor tempo de empresa (ou seja, os trabalhadores com 1 a 10 anos de casa). Ao mesmo tempo, um nível mais elevado de escolarização foi um dos critérios utilizados para selecionar novos trabalhadores que, em tese, não gozavam de experiência nas fábricas contratantes.

Tabela 4 - Distribuição percentual do volume do emprego por sexo e escolaridade, Brasil

\begin{tabular}{c|c|c|c|c|c|c|c|c|c}
\cline { 2 - 10 } Masculino & \multicolumn{10}{c}{ Anos } & $\mathbf{2 0 0 1}$ & $\mathbf{2 0 0 2}$ \\
\cline { 2 - 10 }$y$ & $\mathbf{1 9 9 4}$ & $\mathbf{1 9 9 5}$ & $\mathbf{1 9 9 6}$ & $\mathbf{1 9 9 7}$ & $\mathbf{1 9 9 8}$ & $\mathbf{1 9 9 9}$ & $\mathbf{2 0 0 0}$ & $\mathbf{2 0 0 1}$ & 1,2 \\
\hline Analfabeto & 1,9 & 1,0 & 2,1 & 1,6 & 1,6 & 1,0 & 0,9 & 1,0 & 17,8 \\
\hline Até 4a. Série & 26,5 & 23,1 & 25,5 & 22,5 & 27,6 & 22,9 & 19,4 & 18,9 & 17 \\
\hline Até 8a. Série & 33,4 & 29,2 & 29,6 & 27,9 & 26,8 & 27,2 & $\mathbf{2 9 , 9}$ & 26,3 & 23,7 \\
\hline Até 2o. Grau & 28,0 & 33,6 & 31,7 & 37,2 & 33,9 & 37,3 & 36,6 & 39,6 & 39,5 \\
\hline Até 3o. Grau & 10,2 & 13,0 & 10,8 & 10,8 & 10,1 & 11,6 & 13,1 & 14,2 & 17,9 \\
\hline Ignorado & 0,0 & 0,1 & 0,3 & 0,0 & 0,0 & 0,0 & 0,0 & 0,0 & 0,0 \\
\hline Total & 100,0 & 100,0 & 100,0 & 100,0 & 100,0 & 100,0 & 100,0 & 100,0 & 100,0 \\
\hline
\end{tabular}

\section{Feminino}

\begin{tabular}{c|c|c|c|c|c|c|c|c|c}
\hline Analfabeto & 1,3 & 0,7 & 0,9 & 1,0 & 0,8 & 0,4 & 0,3 & 0,7 & 0,8 \\
\hline Até 4a. Série & 22,8 & 15,3 & 17,6 & 17,0 & 15,6 & 14,4 & 13,7 & 11,8 & 11,4 \\
\hline Até 8a. Série & 22,0 & 13,2 & 20,8 & 19,0 & 15,0 & 18,3 & 21,2 & 20,7 & 15,5 \\
\hline Até 2o. Grau & 28,5 & 32,7 & 30,0 & 34,0 & 33,2 & 31,4 & 30,1 & 29,9 & 28,2 \\
\hline Até 3o. Grau & 25,3 & 37,8 & 30,3 & 29,0 & 35,4 & 35,5 & 34,6 & 36,9 & 44,2 \\
\hline Ignorado & 0,0 & 0,2 & 0,3 & 0,0 & 0,0 & 0,0 & 0,0 & 0,0 & 0,0 \\
\hline Total & 100,0 & 100,0 & 100,0 & 100,0 & 100,0 & 100,0 & 100,0 & 100,0 & 100,0 \\
\hline
\end{tabular}

Fonte: Elaboração a partir da base de dados da RAIS/ MTE.

$(*)$ Incluem-se nos referidos graus de instrução as seguintes categorias:

$4^{\text {a }}$. Série incompleta e $4^{\text {a }}$. Série completa

$8^{\text {a }}$. Série incompleta e $8^{\text {a }}$. Série completa

$2^{\circ}$. Grau incompleto e $2^{\circ}$. Grau completo

$3^{\circ}$. Grau incompleto e $3^{\circ}$. Grau completo

Tabela 5 - Distribuição percentual do volume do emprego por sexo e tempo de serviço, Brasil

\begin{tabular}{c|c|c|c|c|c|c|c|c|c}
\cline { 2 - 10 } Masculino & \multicolumn{10}{c}{ Anos } \\
\cline { 2 - 10 } & $\mathbf{1 9 9 4}$ & $\mathbf{1 9 9 5}$ & $\mathbf{1 9 9 6}$ & $\mathbf{1 9 9 7}$ & $\mathbf{1 9 9 8}$ & $\mathbf{1 9 9 9}$ & $\mathbf{2 0 0 0}$ & $\mathbf{2 0 0 1}$ & $\mathbf{2 0 0 2}$ \\
\hline Ate 2,9 Meses & 3,8 & 2,8 & 2,7 & 2,1 & 1,3 & 2,9 & 4,1 & 10,0 & 2,8 \\
\hline De 3 meses a 1 ano & 9,8 & 16,8 & 9,0 & 6,6 & 13,3 & 10,8 & 9,9 & 9,9 & 10,0 \\
\hline De 1 a 3 anos & 19,5 & 13,4 & 23,2 & 20,9 & 11,8 & 12,6 & $\mathbf{2 1 , 9}$ & 22,4 & 17,2 \\
\hline De 3 a 5 anos & 17,4 & 17,8 & 13,2 & 11,2 & 13,7 & 15,1 & 10,4 & 7,2 & 14,4 \\
\hline De 5 a 10 anos & 28,5 & 27,6 & 31,5 & 34,4 & 29,5 & 26,4 & 22,7 & 20,2 & 19,7 \\
\hline 10 anos ou mais & 21,1 & 21,6 & 20,3 & 24,7 & 30,5 & 32,1 & 31,0 & 30,3 & 35,8 \\
\hline Ignorado & 0,0 & 0,0 & 0,0 & 0,0 & 0,0 & 0,0 & 0,0 & 0,0 & 0,0 \\
\hline Total & 100,0 & 100,0 & 100,0 & 100,0 & 100,0 & 100,0 & 100,0 & 100,0 & 100,0 \\
\hline
\end{tabular}

Feminino
\begin{tabular}{c|c|c|c|c|c|c|c|c|c}
\hline Ate 2,9 meses & 7,6 & 4,6 & 3,4 & 2,9 & 2,1 & 3,5 & 6,2 & 12,3 & 5,6 \\
\hline De 3 meses a 1 ano & 16,0 & 19,2 & 15,7 & 11,6 & 13,9 & 18,5 & 16,9 & 14,6 & 24,0 \\
\hline De 1 a 3 anos & 22,6 & 20,7 & 26,8 & 26,6 & 18,9 & 14,5 & 24,9 & 27,4 & 25,8 \\
\hline De 3 a 5 anos & 17,0 & 17,0 & 13,5 & 15,1 & 17,7 & 15,5 & 11,8 & 9,2 & 12,2 \\
\hline De 5 a 10 anos & 24,6 & 25,1 & 26,0 & 28,7 & 29,7 & 25,4 & 19,9 & 15,7 & 12,7 \\
\hline 10 anos ou mais & 12,1 & 13,4 & 14,5 & 15,1 & 17,8 & 22,7 & 20,2 & 20,9 & 19,7 \\
\hline Ignorado & 0,0 & 0,0 & 0,0 & 0,0 & 0,0 & 0,0 & 0,0 & 0,0 & 0,0 \\
\hline Total & 1000 & 100,0 & 100,0 & 100,0 & 100,0 & 100,0 & 100,0 & 100,0 & 100,0 \\
\hline
\end{tabular}

Fonte: Elaboração a partir da base de dados da RAIS/ MTE. 
Qual o significado dos indicadores apresentados pelo mercado de trabalho neste segmento industrial? Eles denotam que não apenas os atributos adquiridos (escolaridade e experiência), mas também aqueles adscritivos ou biológicos (sexo e idade), juntos, e não de forma excludente, jogaram um importante papel na definição tanto da inserção e permanência, quanto da exclusão de trabalhadoras e trabalhadores. Ademais, em alguns casos, os atributos adscritivos foram justapostos àqueles adquiridos. Sendo, em geral, os (as) mais jovens, menos instruídos (as) e menos experientes os (as) preteridos(as), enquanto os homens, mais velhos, mais instruídos e mais experientes conseguiram permanecer nas empresas após o período mais intenso de reestruturação das empresas ${ }^{8}$.

Embora as mulheres comecem timidamente a ocupar postos técnicos e de operação de campo em algumas fábricas de empresas líderes (Oliveira, Gaio e Bonacim, 2008), há, na prática, uma permanência das assimetrias entre homens e mulheres que se manifesta na presença minoritária das trabalhadoras na produção, sobretudo, na ausência de sua participação nos postos de trabalho intensivos em tecnologia, dotados de maiores graus de responsabilidade, confiança das chefias, remuneração e de conteúdos mais complexos de trabalho, como por exemplo, os postos de controle de processo ${ }^{9}$.

Em contrapartida, com a inclusão da terceirização nas estratégias gerenciais das empresas para concentrar seus esforços em atividades nucleares da produção e com maiores valores agregados, verifica-se um aumento gradativo e significativo da presença de mulheres em etapas produtivas que requerem menor qualificação, menores índices de escolarização, conteúdos mais simples de trabalho e menor remuneração. Este é o caso da produção de mudas de eucalipto, área em que as trabalhadoras terceirizadas substituíram na sua grande maioria a força-de-trabaIho masculina própria, majoritariamente, alocada neste setor num passado recente.

Tal reforço das assimetrias de poder na esfera da produção é feito ao mesmo tempo em que são enaltecidas pelas empresas, as iniciativas tomadas no sentido de promover uma maior democratização dos espaços anteriormente monopolizados pelos homens nas fábricas. Todavia, o maior acesso das mulheres às empresas e às fábricas nos últimos anos não significou que houve um ganho de poder efetivo das trabalhadoras na produção. Na realidade, os postos-chave na produção e os espaços de poder na fábrica (aí entendidos os postos de operação com maiores status e aqueles de chefia nas unidades industriais) continuam e, ao que parece, permanecerão 'blindados', sendo ainda redutos marcadamente masculinos.

Outra questão que merece uma análise cuidadosa é de que formas e em que medida o processo de reestruturação organizacional via transformações na organização do trabalho, tendo na modernização tecnológica uma relevante mediadora, tem produzido e estruturado novas relações de poder no interior da fábrica e nos locais de trabalho, afetando a vida dos trabalhadores, e modificando as relações de força entre os diversos atores envolvidos na produção e que lograram permanecer nas empresas após os ajustes realizados no mercado de trabalho.

Nossa hipótese é a de que as mudanças na organização do trabalho ocorridas nas seis empresas estudadas, quaisquer que sejam elas (alterações no padrão tecnológico de controle analógico para digital, redução do número de classificações ocupacionais e aumento do número de tarefas, alterações da estrututura hierárquica, rotação de postos e mobilidade interna, trabalho em grupo ou em equipe, transferência de responsabilidade e autonomia aos trabalhadores, redução do controle e da supervisão direta, centralização das salas de controle, flexibilidade funcional entre atividades de operação de controle e de operação de campo, multifuncionalidade, etc.), para além

8 Indicadores semelhantes foram encontrados por Guimarães (2004) para a indústria química e petroquímica brasileira.

9 De outro modo, como explicar o fato de que apenas em ocasiões específicas, como por exemplo, nos meses mais adiantados de gravidez, as operadoras de área sejam autorizadas a ocupar os postos de controle na produção? 
de buscar extrair eficiência técnica e maior eficácia da força-de-trabalho, guardam no seu conjunto um elemento político comum entre si, qual seja: a reestruturação das relações de poder no interior das fábricas, tendo na participação da mão-de-obra uma mediadora não desprezível.

Assim, ao avaliar o conjunto das alterações na forma como o trabalho é organizado e como a força-de-trabalho é distribuída e utilizada na produção, seja do ponto de vista técnico, seja do ponto de vista político, é possível decifrar um dos elementos-chave das estratégias gerenciais, qual seja, a participação, incitada a se manifestar através da adesão e do empenho dos trabalhadores. Essas mudanças que evoluem de uma organização do trabalho baseada na perspectiva individual e na supervisão direta, para uma organização do trabalho fundamentada na dimensão grupal em que os trabalhadores internalizam uma espécie de controle social sobre o seu próprio trabalho, elevam a contribuição dos trabalhadores na produção (Bélanger, 2000). Neste sentido, os novos métodos de organização do trabalho que pressupõem a participação reclamam, sobretudo, tanto o engajamento psíquico, quanto o conhecimento tácito dos trabalhadores para reduzir desperdícios, resolver problemas com maior velocidade e regular o processo produtivo. Portanto, uma dimensão comum das alterações na organização do trabalho é a de conseguir mobilizar uma maior participação de todos na produção.

A participação dos trabalhadores permite que os métodos de gestão 'aconteçam', se concretizem e que saiam do plano das estratégias para o 'mundo real' e que sejam finalmente sedimentados. A participação é, portanto, um elemento-chave para alcançar as metas delineadas pelas estratégias de negócios das empresas. É também um instrumento eficaz para alterar a correlação de forças e tornar as empresas menos vulneráveis, desbaratando feudos de poder nos locais de trabalho ao diminuir a importância estratégica das chefias e de algumas categorias de trabalhadores ou para quebrar monopólios do saber colocando-o à disposição da produção e das empresas.

A participação pode ser estimulada a se manifestar por meio de três dimensões. A primeira delas dá-se via modificações na organização do trabalho que, realizadas de uma forma tal, acabam desencadeando o emprego maior de energia e empenho por parte dos trabalhadores, incitando a cooperação mútua entre eles.

A segunda estratégia é levada a termo por meio da introdução de dispositivos participativos. Estes dispositivos prevêem a formação de grupos de trabalho (os chamados grupos de melhoria), os quais podem reunir trabalhadores da produção e da manutenção, engenheiros, técnicos, integrantes da gerência, fornecedores de equipamentos e prestadores de serviço com objetivo de solucionar problemas de produção, qualidade, custos, desperdícios, segurança ou de impactos ambientais ${ }^{10}$.

Há, ainda, uma terceira forma de estimular a participação que é realizada por meio do apelo ao comprometimento e à dimensão afetiva dos trabalhadores e, para tanto, as estratégias e os instrumentos de comunicação com o empregado jogam um papel crucial no sentido de construir um campo relacional, permeado de significados simbólicos, entre as empresas e os seus trabalhadores. Neste particular, conforme elucidam Pagès et alli (1993), a contribuição dos indivíduos para a produção passa a depender de forma significativa da persuasão, do enquadramento do indivíduo e da integração de sua visão social de mundo ao quadro de referências (crenças e valores) da empresa.

As empresas estudadas passaram a incentivar a participação dos trabalhadores na elaboração de inovações incrementais para o processo produtivo por meio dos programas participativos em melhoria contínua. A finalidade deste procedimento é trazer à tona um conhecimento tácito que foi desenvolvido pelos trabalhadores ao longo dos anos de experiência com a fábrica, transformando-o em inovações incrementais que elevem a eficiência do processo produtivo e a maximi-

10 Os problemas e as soluções são apresentados pelos trabalhadores e o papel dos engenheiros e representantes da direção é analisar a viabilidade técnica e econômica das proposições, bem como orientar os trabalhadores na realização dos projetos de melhoria emitindo pareceres concernentes à possibilidade de sua execução. 
zação da lucratividade das empresas. Por meio desse mecanismo as idéias dos trabalhadores são verbalizadas, estudadas e somente implantadas se constatada sua capacidade de reduzir custos, diminuir perdas, aumentar a capacidade produtiva, reduzir o número de paradas operacionais, eliminar causas de desvios de qualidade, reduzir o impacto ambiental, aumentar a receita ${ }^{11}$.

Embora os trabalhadores não sejam obrigados a colaborar com sugestões, aqueles que o fazem são vistos com 'bons olhos' pelas chefias e passam a gozar de determinadas prerrogativas tanto nas avaliações de desempenho, quanto em questões que envolvem oportunidades concedidas pelas empresas, tais como: financiamento de participações em congressos e/ou reuniões científicas para apresentar um trabalho de melhoria, pagamento de viagens para treinamento e/ ou cursos, etc.. Ações que têm o propósito de estimular o sentimento de competição e de disputa entre os trabalhadores, na medida em que contrapõem no terreno da competência, da capacidade e da aprovação pela empresa aqueles que têm versus os que não têm melhorias apresentadas.

Alguns trabalhadores, todavia, percebem este movimento de exacerbação da concorrência ensejado pelas empresas, denunciando que tais programas instigam o conflito e uma corrida desenfreada entre os colegas para apresentar 'em primeira mão', como num 'furo de reportagem', a propriedade das idéias, algumas das quais, entretanto, surgiram de discussões conjuntas entre os operadores durante a jornada de trabalho.

Desse modo, há, nos últimos anos, uma maior disposição das empresas para discutir idéias e/ou inovações incrementais propostas pelos trabalhadores. Como há também, uma maior inclinação em ouvir opiniões e discutir com os trabalhadores as mudanças que serão implementadas na produção. Entretanto, percebe-se pelo teor do discurso dos trabalhadores que o debate acerca dessas alterações limita-se ao aspecto técnico dos equipamentos e/ou da produção. Tratase de uma participação sem poder, para usar a expressão cunhada por Lapointe (2000; 2000-a), isto é, aquela que visa simplesmente à melhoria do desempenho do processo produtivo, mas que não contempla questões relativas às relações de trabalho e de emprego, ou ainda, a apropriação do processo de tomada de decisões pelos trabalhadores, ou, o compartilhamento do poder de decisão dos empregadores com esses últimos e seus representantes sindicais ${ }^{12}$.

Qual o real significado da participação dos trabalhadores num contexto em que recrudescem os apelos da globalização e da competitividade? A participação dos trabalhadores é um dos eixos basilares do processo de reestruturação porque fator de competitividade para as empresas. O mecanismo da participação ajuda a trazer à tona uma preciosidade oculta, protegida, desconhecida da empresa e fora de seu controle, porque interior aos indivíduos. Ou seja, a participação permite explicitar o conhecimento tácito acumulado pelos trabalhadores ao longo dos seus anos de experiência. Numa conjuntura em que as estratégias gerenciais das empresas assemelham-se cada vez mais entre si neste setor, o grau e a qualidade da participação dos trabalhadores de uma dada empresa, isto é, seus recursos e capacidades (BARNEY E HERSTERLY, 2008), podem diferenciá-la das demais concorrentes no que tange ao processo inovativo, ao desempenho da produção, à eliminação dos desperdícios e à redução de custos. Na visão de Barney e Hesterly (2008), a mobilização e coordenação adequada dos recursos e capacidade (financeiros, físicos, humanos e organizacionais) de uma empresa podem gerar resultados potencialmente relevantes à competitividade de seu negócio, como por exemplo, a neutralização de ameaças e, sobretudo, a exploração de oportunidades 11 Esses programas, segundo Carvalho (1994-a) e Kern e Schumann (1998), têm como objetivo a constituição de espaços e instrumentos formais para utilizar o conhecimento do processo produtivo acumulado pelos operadores ao longo dos anos a fim de melhorar a competitividade das empresas. Esta prática também mostra sua eficácia na elevação do aprendizado tecnológico das plantas produtivas sendo utilizada como modalidade de treinamento para os trabalhadores com menos experiência, os quais participam dos grupos de discussão de melhorias junto aos operadores mais experientes em algumas fábricas pesquisadas.

12 Para esse autor, a participação com poder implicaria a participação da mão-de-obra na tomada de decisões. Quanto à participação sem poder, os trabalhadores limitar-se-iam à comunicação de determinadas informações acerca da produção e à emissão de suas respectivas opiniões, reservando-se a direção o direito de decidir (Lapointe, 2000-a). 
alinhadas às suas prioridades estratégicas e/ou lacunas ainda não trabalhadas por seus concorrentes. Daí a importância dada à participação dos trabalhadores.

No entanto, se a experiência, o conhecimento tácito e a participação dos trabalhadores são aspectos cruciais para as empresas levarem a cabo suas estratégias de mercado (aliados a todo arsenal tecnológico e organizacional), é possível identificar a permanência de uma relação de exploração, não apenas no que concerne ao valor pago pela expropriação da força-de-trabaIho, mas no que se refere às contrapartidas pela apropriação do conhecimento tácito dos trabaIhadores e, sobretudo, às compensações pelo emprego de energias (afetivas, psíquicas, físicas, cognitivas, etc.) que fundamentam a relação de comprometimento.

Em face de tais inflexões qualitativas, na rotina das empresas e dos locais de trabalho e na vida dos atores, como fazer consolidar as modificações e ainda que as mesmas sejam compreendidas, acolhidas e introjetadas pelos indivíduos como as mais corretas do ponto de vista da eficiência, da competitividade e da sobrevivência de suas empresas (mesmo aquelas cuja finalidade é diminuir o poder dos indivíduos ou evitar a apropriação do poder por um indivíduo ou um grupo)? Qual o lugar e o significado das políticas de gestão da mão-de-obra num contexto de intensas transformações nesta cadeia produtiva, nas empresas, na gestão da produção e do trabalho? Além disso, qual a relação entre a globalização da produção, a redefinição das estratégias gerenciais das empresas, a reestruturação produtiva, as mudanças na organização do trabalho e as políticas de recursos humanos?

Em primeiro lugar, além das transformações na organização do trabalho que levam a um aumento da participação da mão-de-obra, outras medidas são empregadas para maximizar o potencial de contribuição e de comprometimento dos trabalhadores e, assim, extrair maior quantidade possível de trabalho vivo: as políticas de pessoal. As mudanças nas políticas de gestão de recursos humanos constituem, então, o terceiro pilar do processo de reestruturação, ao lado das alterações na produção e na organização do trabalho (SOUZA E BASTOS, 2008). Como observou Bélanger (2000), a introdução conjunta de inovações tecnológicas no plano da fábrica e de inovações na organização do trabalho e na gestão de recursos humanos é tributária de uma dada coerência interna na medida em que estas medidas interligam-se e complementam-se entre si, influenciando a obtenção da produtividade e da qualidade.

Em segundo lugar, cabe considerar o real significado das políticas de recursos humanos num contexto de transformações na divisão internacional do trabalho em que se aprofundam as relações hierárquicas no interior da cadeia produtiva global e a inserção das empresas brasileiras nessa cadeia como fornecedoras de celulose de mercado aos principais produtores tradicionais de papel e seus derivados. A intensificação desta inserção influenciou as estratégias gerenciais das empresas brasileiras desencadeando uma série de transformações sistêmicas. Desta forma, a produção de novas formas de consenso entre os trabalhadores, conforme observou Guimarães (2004) para a químico-petroquímica brasileira, tornou-se um componente essencial do redesenho das estratégias das empresas e de seu processo de reestruturação, sendo a qualificação, a formação profissional e o treinamento da mão-de-obra, a política salarial e as políticas de estabilização da força-de-trabalho algumas das variáveis-chaves utilizadas pelas empresas para construir este consentimento, bem como para legitimar e dar sustentação àquelas mudanças observadas na esfera da produção e da organização do trabalho ${ }^{13}$.

Nossa hipótese é a de que as relações de poder também se enraízam na prática cotidiana das empresas através das políticas de recursos humanos. Dito de outro modo, as políticas de gestão do trabalho praticadas pelas empresas estudadas - quais sejam: os novos requisitos para seleção e retenção da força-de-trabalho, a política de treinamento, o estímulo à elevação dos ní13 Consultar Lapointe et alli (2002-c). 
veis de instrução formal dos trabalhadores, a política salarial e a modificação no perfil tradicional das carreiras verticais - têm se constituído como mecanismos de poder para assegurar o controle social sobre a mão-de-obra, interiorizar comportamentos e princípios, convencer os trabalhadores, construindo assim o seu consentimento. Além disso, tais políticas se afirmam como um dos eixos de sustentação do processo de reestruturação produtiva das empresas, funcionando como amálgama seja para cimentar as mudanças e os novos métodos de gestão, seja para obter a adesão dos trabalhadores às estratégias empresariais.

Assim, as políticas de recursos humanos mostraram uma enorme capacidade de revigoramento, mantendo ainda um lugar capital na indústria de processo contínuo que sempre se caracterizou por cultivar e nutrir políticas ousadas de gestão da mão-de-obra. Isto porque, o extenso conjunto de benefícios salariais e extra-salariais que fundamentavam a relação de confiança e de compromisso dos trabalhadores com as empresas e a produção também passou a abarcar o apelo à subjetividade dos trabalhadores, a assimilação às novas regras (simbólicas inclusive) e a premiar o grau de identificação dos trabalhadores com as suas empresas.

\section{COMENTÁRIOS FINAIS}

O ambiente externo joga um relevante papel como indutor das mudanças que acontecem no interior das empresas (SARAIVA, 2008). No entanto, elementos tais como a cultura da empresa (Vargas, 2008; Barbosa, 2002), as escolhas estratégicas e gerenciais (Morgan, 1996) e os aspectos institucionais (Powell e DiMaggio, 1991) e regulatórios não se colocam como desimportantes no processo de percepção, orientação, negociação e validação das mudanças.

Dentro desta visão, a pesquisa buscou realizar uma análise que situasse o trabalho como um dos elementos centrais do processo de globalização e que considerasse os trabalhadores e suas entidades representativas como atores inseridos na dinâmica dos processos que levam a globalização. Isto porque as escolhas, as estratégias e as ações (conformismo, negociação ou resistência) desses sujeitos em locais específicos, reais e concretos - articuladas nos níveis nacional, regional e internacional - podem influenciar a dinâmica e o conteúdo das mudanças nos regimes produtivos e nos regimes regulatórios, podendo reforçar as tendências ou as contra-tendências relativas à globalização e provocar alterações em distintos lugares e contextos (Araújo, 2001; Waddington, 1999).

Para tanto, tomou-se como exemplo o caso da indústria brasileira de celulose de mercado. Trata-se de um setor francamente exposto ao comércio internacional e à globalização. Os atributos de internacionalização desse setor combinados às especificidades da indústria de processo contínuo, ao perfil da mão-de-obra aí empregada e às políticas de gestão do trabalho, auxiliam na compreensão das tendências pavimentadas pela realidade, embora não tenha sido nossa intenção tecer considerações de conteúdos generalizantes acerca do processo de globalização e reestruturação.

A percepção dos trabalhadores sobre as mudanças ocorridas nos regimes de produção e que alteraram as relações nos locais de trabalho constituíram elementos fundamentais para informar a análise e sustentar o argumento central do artigo, qual seja: a de que as mudanças associadas à globalização transformam e (re)estruturam as relações de poder não somente entre países e no interior das cadeias produtivas (tal como amplamente debatido pela literatura especializada), mas têm um rebatimento importante no interior das fábricas e nos locais de trabalho, modificando a correlação de forças entre os diversos atores envolvidos na produção. Modificação que é mediada pela participação da mão-de-obra e que está associada ao refinamento das formas de construir o consentimento e obter o controle social dos trabalhadores via convencimento (persuasão), disciplina, autocontrole e o olhar permanente de uns sobre os outros. 
Neste sentido, a conquista da adesão dos trabalhadores pode ser trabalhada mediante duas lógicas. Uma lógica coercitivo-compulsória, dadas as suas características de arbitrariedade e unilateralidade, na medida em que os trabalhadores são impelidos e praticamente constrangidos a aceitar as regras do jogo se quiserem preservar o seu emprego. No entanto, apesar da ameaça real do desemprego, esta lógica árida não se sustentaria por muito tempo, sucumbiria, pois não seria capaz de fecundar o compromisso dos trabalhadores. Ela irromperia algumas feridas e deixaria as marcas do ressentimento, destruiria a confiança e a memória de sentimentos e emoções construídas ao longo dos anos entre os trabalhadores e suas empresas, fertilizaria o terreno para a emergência de conflitos e reivindicações (individuais e coletivas) e ainda abriria uma brecha a ser ocupada pelos sindicatos. Também não seria capaz de promover o afeto e a identificação dos trabalhadores com suas empresas, o zelo e o amor e a dedicação pelo trabalho, o interesse dos indivíduos pelo crescimento das firmas, a mobilização de suas energias e a doação de seu tempo para a participação. Desse modo, num longo prazo, as empresas encontrariam dificuldades para pôr em prática suas estratégias gerenciais e de conquistas de mercados, destruiriam o potencial de seus recursos e capacidades.

Portanto, o engajamento observado nas empresas pesquisadas não pode ser explicado apenas mediante uma lógica que constrange, exige, impõe e penaliza os indivíduos. Foi possível observar a presença de uma lógica relacional adubada por um quadro de referências simbólicas, morais, ideológicas e culturais. Lógica nutrida por um conjunto de contrapartidas (materiais e simbólicas), em torno das quais se estruturam a persuasão, o comprometimento e o consentimento dos trabalhadores em direção às suas empresas e, por conseguinte, às novas práticas de gestão da produção e do trabalho. Tais práticas têm sido elaboradas e postas em funcionamento para extrair maior eficácia dos trabalhadores e atingir os objetivos das firmas.

A comunicação das empresas com os trabalhadores constitui uma das dimensões centrais do processo de reestruturação produtiva das firmas pesquisadas. De fato, verificou-se que a comunicação - através dos vários instrumentos concebidos para tal - constituiu um mecanismo relevante de mediação no relacionamento entre as empresas e seus empregados, familiares de trabalhadores, prestadores de serviço, alcançando também os clientes e as comunidades locais. Ela atuou tanto para divulgar as mudanças ocorridas e reforçar a necessidade de introjetar os novos comportamentos valorizados e efetivamente exigidos pelas empresas, quanto para construir ou (re)elaborar a representação simbólica das empresas no imaginário dos seus diversos públicos e/ou intervir nas representações mentais que esse público constrói sobre as companhias.

A difusão e o compartilhamento de informações com os trabalhadores da produção (as quais, num passado recente, eram controladas pelas chefias e pela engenharia) constitui um elemento crucial para entender algumas das transformações na organização do trabalho. A quebra do monopólio sobre a informação foi mediada pelas novas tecnologias e pelo enxugamento dos níveis hierárquicos. Ao mesmo tempo, constituiu um mecanismo político para desmantelar 'feudos' de poder dentro das fábricas, permitindo ainda esvaziar a autoridade das chefias imediatas dos trabaIhadores na medida em que aos operadores foram atribuídas e transferidas maior responsabilidade e autonomia sobre seu trabalho. Esse processo de 'democratização' das informações aos trabalhadores do chão-de-fábrica constitui ainda um dos elementos explicativos do êxito que as empresas têm obtido, nos últimos anos, no que concerne à elevação da produtividade, à melhoria da qualidade do que é produzido, à eliminação de perdas e desperdícios, à redução de paradas na produção ocasionada por avarias em equipamentos ou acidentes no trabalho, ao aumento da participação.

$O$ atual processo sistêmico de reestruturação produtiva ocorrido nas empresas brasileiras do segmento de celulose de mercado, a partir dos anos 90, deve ser compreendido como parte do processo de globalização e de aprofundamento da inserção deste setor na divisão interna- 
cional do trabalho como produtor especializado. Sistêmica, a reestruturação alcançou um amplo espectro: desde a reestruturação das cadeias no plano internacional, passando pela redefinição das estratégias gerenciais das empresas, ultrapassando o interior de suas fronteiras com mudanças nas relações com as comunidades e as firmas que integram a sua cadeia de fornecimento de produtos e serviços (Guimarães, 2004) e, contemplando também, a reformulação das estratégias sindicais mesmo que estas ainda estejam em processo de amadurecimento.

As especificidades reveladas pela reestruturação no contexto das empresas estão relacionadas a uma série de elementos internos e externos: cultura gerencial, vocação competitiva, tamanho, origem, recursos financeiros, especificidades regionais, investimento das empresas na capacitação das comunidades locais, mas também se relacionam às diferentes formas de construir o consentimento e de conquistar a participação dos seus trabalhadores, bem como ao grau de interferência das entidades sindicais locais nas atividades e na reestruturação das empresas.

Os indicadores do mercado de trabalho indicaram que não apenas os atributos adquiridos (escolaridade e experiência), mas também aqueles adscritivos (sexo e idade) contribuíram para definir as chances de inserção, permanência e exclusão dos trabalhadores, sendo que, em alguns casos, os atributos biológicos condicionaram as escolhas mais que a qualificação formal. Tendo sido possível apontar para um crescimento da participação de trabalhadoras, embora elas ainda não tenham logrado alcançar os postos estratégicos de produção e de comando nas empresas, dado que a estratificação em torno do sexo ainda se faz presente nesse segmento.

Através de decisões gerenciais 'técnicas' para alcançar maiores índices de eficiência e de rendimento efetivo da força-de-trabalho, mas que na realidade ocultam uma dimensão 'política', as correlações de força entre superiores imediatos e trabalhadores do chão-de-fábrica foram reconfiguradas. Isto se deu, preferencialmente, pela via do compartilhamento de informações da produção, da flexibilização funcional, da transferência de responsabilidade e de autonomia aos operadores, das alterações na estrutura hierárquica e da participação da mão-de-obra. A autoridade hierárquica de alguns superiores imediatos dos trabalhadores foi em parte esvaziada.

Essa perda de poder e de espaço foi mediada pelas novas tecnologias, por alterações na organização do trabalho, mas também por decisões gerenciais socialmente condicionadas de desconcentrar e despersonificar o poder disciplinar da figura de indivíduos, pulverizando-o entre os trabalhadores, a fim de manter um controle social mais sutil e eficaz, porque controle 'de si mesmo' e 'de uns sobre os outros', sobre a força-de-trabalho.

As políticas de recursos humanos se atualizaram e ganharam vigor para reavivar o consentimento dos trabalhadores. A tradicional cesta de benefícios salariais e extra-salariais que pavimentavam a relação de confiança e de comprometimento com a produção estendeu-se à premiação do mérito -, traduzido aqui como conquista da dedicação e captura da subjetividade dos trabalhadores.

Além da estratégia da conquista de corações e mentes dos trabalhadores, em alguns casos, a ofensiva das empresas foi a de desestabilizar o relacionamento dos trabalhadores com seus representantes e de esvaziar a autoridade sindical. Isto porque, a suposta 'perda' de benefícios monetários que eram concedidos acima dos percentuais previstos pela legislação trabalhista foi utilizada como artifício político para questionar a legitimidade das entidades sindicais em presença, embora os valores 'perdidos' estivessem sendo convertidos em benefícios de qualificação para os empregados com perspectiva de retorno sobre o investimento para as empresas.

Neste contexto, a postura defensiva dos sindicatos nas negociações coletivas foi essencial para brecar os efeitos negativos do processo de globalização e de aprofundamento da reestruturação no setor e para assegurar algumas garantias para os trabalhadores sobreviventes. Mas os sindicatos papeleiros também colocaram em prática estratégias ofensivas, reformulando a 
organização sindical oficial para aumentar o seu poder de enfrentamento na correlação de forças com as empresas, negociando em conjunto, disputando com sindicatos fracos e 'pelegos' a representação dos trabalhadores terceirizados ou ainda a direção de entidades sindicais e aliando-se internacionalmente com organizações sindicais mais fortes.

É desta forma que, a nosso ver, qualquer análise acerca do processo de globalização deve situar o trabalho como um dos seus elementos centrais e considerar os trabalhadores $\mathrm{e}$ suas entidades representativas como atores inseridos na dinâmica dos processos que levam a globalização. Isto porque as escolhas, as estratégias e as ações (conformismo, negociação ou resistência) desses sujeitos em locais específicos, reais e concretos - articuladas nos níveis nacional, regional e internacional - podem influenciar a dinâmica e o conteúdo das mudanças nos regimes produtivos e nos regimes regulatórios, podendo reforçar as tendências ou as contratendências relativas à globalização e provocar alterações em distintos lugares e contextos (Araújo, 2001; Waddington, 1999).

O nível local e sua articulação com outros níveis de ação - cujo espectro de alianças pode variar do local ao global - pode ser tanto o núcleo da experiência concreta dos trabalhadores, quanto o seu núcleo de resistência à globalização nos seus aspectos mais assimétricos e contraditórios (Araújo, 2001). A [micro] luta dos trabalhadores no interior das fábricas ou na esfera local, não deve ser desprezada porque capaz de produzir efeitos significativos na [macro] dinâmica do processo de globalização, de transformação dos regimes de produção e dos regimes regulatórios e, portanto, no curso da História.

\section{REFERÊNCIAS}

ABRAMO, L. (2000). Mercado de trabajo, flexibilización y nuevas formas de relación. In: Cadernos do CESIT, Texto para discussão no.29, Campinas, julho. 42p.

ARAÚJO, A.M.C. (2001). Globalização e Trabalho : uma resenha da literatura, 57p, mímeo.

ARAUJO, A.M.C., CARTONI, D. e JUSTO, C. (2001). "Reestruturação Produtiva e negociação coletiva nos anos 90". In: Revista Brasileira de Ciências Sociais, vol. 16, n. 45, fevereiro, p.85-112.

ARAÚJO, A.M.C.; GITAHY, L.; RACHID, A.; CUNHA, A. (2004). Globalização, estratégias gerenciais e respostas operárias: um estudo comparativo da indústria de linha branca. Relatório Científico apresentado à Fundação de Amparo à Pesquisa do Estado de São Paulo (FAPESP). 336p.

BARBOSA, L. (2002). Cultura e Empresas. Ed. Jorge Zahar. Coleção Ciências Sociais Passo-apasso, $55 \mathrm{p}$.
BARNEY, J.; HESTERLY, W.S. (2008). Administração Estratégica e Vantagem Competitiva. São Paulo: Pearson Prentice Hall Editora.

BÉLANGER, J. (2000). L'influence de la participation des employés sur la productivité: état de la recherche. In: Gazette du travail, vol. 4, no. 4, pp. 72-88.

CARVALHO, R.Q. (1994-a). "Capacitação Tecnológica, Revalorização do Trabalho e Educação". In: FERRETI, C. et allii (orgs.). Novas Tecnologias, Trabalho e Educação: um debate multidisciplinar. Petrópolis: Vozes. p. 93-127.

GUIMARÃES, N. A. (2004). Caminhos cruzados: estratégias de empresas e trajetórias de trabalhadores. $1^{\mathrm{a}}$. edição. Editora 34. 405p.

HARVEY, P-A. (2003). Mondialisation et travail. In: Institut de recherche et d'informations socio-économiques (http://www.irisrecherche.qc.ca). Site internet acessado em 21/04/2004. ISBN 2-923011-04-X, 68p.

HELD, D.; McGREW. A.; GOLDBLATT, D.; e PERRATON, J. et alli (2000). Global 
Transformations: Politics, Economics and Culture. Polity Press. 515p.

HIRST, P. e THOMPSON, G. (1998). Globalização em questão: a economia internacional e as possibilidades de governabilidade. Petrópolis: RJ: Vozes. 364p.

KERN, H. e SCHUMANN, M. (1998). Continuidade ou Mudança de Rumo? O Modelo Alemão de Produção na Encruzilhada. In: Contemporaneidade e Educação, Ano III, no. 04, dez, 151-161p..

LANGLOIS, P. (1996). La restructuration de l'industrie canadienne des pâtes et papiers : impacts sur la main-d'oeuvre et les communautés non-metropolitaines. Mémoire presenté comme exigence partielle de la Maîtrise en Sociologie, juillet, 268p.

LAPOINTE, P.-A. (1996-a). Cascades Jonquière: paradoxe organisationnel et blocage institutionnel. In: CHAYKOWSKY, R. ; LAPOINTE, P.-A ; VALLÉE, G. Et VERMA, A.. (Orgs.). La représentations des salariés dans le contexte du libre échange et de la déréglementation. Sélection de textes du XXXIIle. Congrès de I'ACRI. Pp. 143-164.

LAPOINTE, P.-A. (1996-b). Participation et partenariat à Cascades-Jonquière: impasse temporaire ou impossible projet? Cahier du Crises, no. 9604, avril, 79p. Disponível em: http://www.crises.uqam.ca/cadis.htm.

LAPOINTE, P.-A. (2000-a). Partenariat, avec ou sans démocratie. In: Cahiers du CRISES, Collection 'Working Papers', no. 0015, 46p., octobre. Disponível em: http://www.crises. uqam.ca/cadis.htm.

LAPOINTE, P.-A. (2000-b). Participation et démocratie au travail. In: Cahier du CRISES, Collection 'Working Papers', no. 0014, 19p. Conférence présentée au 12e. Congrès Associotion internationale des relations professionelles, mai-jun, octobre,Tókio. Disponível em: http://www.crises.uqam.ca/ cadis.htm.

LAPOINTE, P.-A. (2000-c). Partenariat et participation syndicale à la gestion: le cas de Tembec. In: Cahiers du CRISES, Collection 'Working Papers', no. 0020, novembre, 48p. Disponível em: http://www.crises.uqam.ca/ cadis.htm.

LAPOINTE, P.-A. (2002-c); CUCUMEL, Guy; BÉLANGER, Paul R.; LÉVESQUE, Benoît; LANGLOIS, Pierre. Innovations en milieu de travail dans le secteur manufacturier au Québec. In: Cahiers du CRISES, Collection 'Working Papers', no 0212. Texte soumis pour publication dans Recherches sociographiques, octobre, 28p. Disponível em: http://www. crises.uqam.ca/cadis.htm.

LÉVESQUE, C. e MURRAY, G. (2003). Le pouvoir syndical dans l'économie mondiale: clés de lecture pour un renoveau. In: Révue du Institut de recherches économiques et sociales (IRES), no. 41, 2003/1. Disponível em: http://www. ires-fr.org/files/publications/revue/r41/r413. pdf. Site internet acessado em 21/04/2004. $28 p$.

MIRANDA, S. (2009). O tabu do poder e da política nos estudos organizacionais.In: Rev. Adm. UFSM, Santa Maria, v. 2, n. 1, p. 490-501, mai./ago. 2009.

MOREAU, M-A. e tRudeau, G. (1998). Le droit du travail face à la mondialisation de l'économie. In: Relations industrielles/ Industrial Relations, volume 53, no. 01 - ISSN 0034-379X. 39p.

MORGAN, G. (1996). Imagens da Organização. São Paulo: Atlas.

OLIVEIRA, A. R. de; GAIO, L. E.; BONACIM, C. A. G. (2008). Relações de gênero e ascensão feminina no ambiente organizacional: um ensaio teórico. In: Rev. Adm. UFSM, Santa Maria, v. 2, n. 1, p. 80-97 jan./abr. 2009.

PAGÈS. M.; BONETTI, M.; GAULEJAC, V. e DESCENDRE, D. (1993). O poder das 
organizações. São Paulo : Editora Atlas. 234p.

POCHMANN, M. (2002). O emprego na

globalização: a nova divisão internacional do trabalho e os caminhos que o Brasil escolheu. $1^{\text {a. }}$ re-impressão. São Paulo: Boitempo Editorial. 151p.

POWELL, W; DiMAGgiO, P. (1991). The New Institutionalism in Organizational Analysis. Chicago: The University of Chicago Press.

SARAIVA, L. A. S. (2010). Sobrevoando analiticamente as teorias da administração. In: Rev. Adm. UFSM, Santa Maria, v. 3, n.1, p. 2640, jan./abr. 2010.

SCHOLTE, J.A. (2000). Globalization: a critical introduction. Macmillan Press Ltd.. 361p.

SOUZA, J. J.; BASTOS, A. V. B. (2008). Gestão de pessoas e a construção da inovação organizacional: uma análise do pensamento gerencial. In: Rev. Adm. UFSM, Santa Maria, v. 1, n. 2, p. 291-305, mai./ago. 2008

VARGAS, N. (2008). Organizações em Ambientes Internacionais Turbulentos: estudo de uma construtora multinacional brasileira. Tese de Doutorado apresentada à Escola Politécnica da Universidade de São Paulo. $161 \mathrm{p}$.

VASCONCELLOS, E. (2008). Internacionalização, Estratégia e Estrutura: o que podemos aprender com o sucesso da Alpargatas, Azaléia, Fanem, Odebrecht, Voith e Volkswagen. São Paulo: Atlas.

WADDINGTON, J. (1999). Situating Labour within the Globalization Debate. In: WADDINGTON, J. (Ed.). Globalization and Patterns of Labour Resistance. Mansell: London and New York. 29p.

YIN, R. K. (2001). Estudo de Caso: planejamento e métodos. 2a. edição. Porto Alegre: Bookman. 200p. 